This item was submitted to Loughborough's Research Repository by the author.

Items in Figshare are protected by copyright, with all rights reserved, unless otherwise indicated.

\title{
Temperature cycling of surface mounted thick film 'zero-ohm' jumpers
}

PLEASE CITE THE PUBLISHED VERSION

PUBLISHER

(C) Emerald

LICENCE

CC BY-NC-ND 4.0

REPOSITORY RECORD

Whalley, David C., and D.S. Campbell. 2019. "Temperature Cycling of Surface Mounted Thick Film 'zero-ohm' Jumpers”. figshare. https://hdl.handle.net/2134/3775. 
This item was submitted to Loughborough's Institutional Repository (https://dspace.lboro.ac.uk/) by the author and is made available under the following Creative Commons Licence conditions.

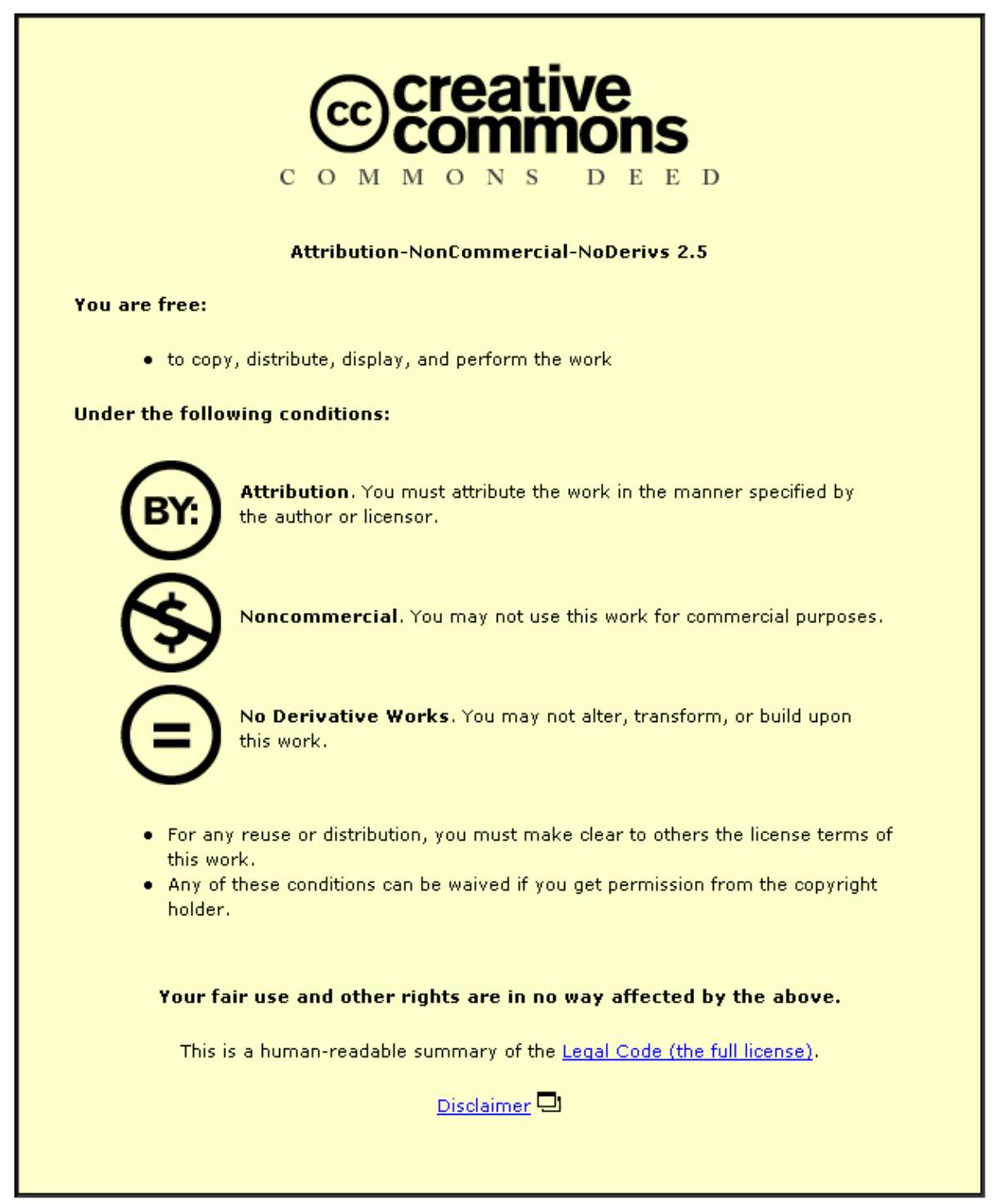

For the full text of this licence, please go to: http://creativecommons.org/licenses/by-nc-nd/2.5/ 


\title{
Temperature Cycling of Surface Mounted Thick Film
}

\section{'Zero-ohm' Jumpers}

\author{
D. C. Whalley and D. S. Campbell \\ Electronic Component Technology Group, \\ Department of Electronic and Electrical Engineering, \\ University of Technology, Loughborough, \\ Leicestershire, England
}

\begin{abstract}
Thermal cycling tests for surface mounted components are usually taken around a mean temperature of approximately $35^{\circ} \mathrm{C}$ (e.g., $-55^{\circ} \mathrm{C}$ to $+125^{\circ} \mathrm{C} ;-40^{\circ} \mathrm{C}$ to $+110^{\circ} \mathrm{C}$ ). To test the effect of different maximum temperatures thermal cycling tests using a lower temperature of $-55^{\circ} \mathrm{C}$ have been conducted with alumina/thick film 'zero-ohm' jumper chips with nickel barriers. These are connected in series chains and wave soldered on to FR-4 test coupons (128 chips/coupon).

The test regimes used were $-55^{\circ} \mathrm{C}$ to $+5^{\circ} \mathrm{C}$; $+65^{\circ} \mathrm{C}$; $+95^{\circ} \mathrm{C},+110^{\circ} \mathrm{C}$ and $+125^{\circ} \mathrm{C}$. Resistance changes before and after cycling were observed at room temperature. After 100 cycles changes of approximately $+200 \mathrm{~m} \Omega$ were observed against a total resistance of $5.5 \Omega$. However, more detailed examination showed that a top temperature of $+95^{\circ} \mathrm{C}$ gives optimum results with a total change over 100 cycles of $+4.9 \%$.
\end{abstract}




\section{INTRODUCTION}

The introduction of any new manufacturing technology brings with it the requirement of an analysis of any reliability hazards associated with it. It is agreed $[1,2,3]$ that in the case of surface-mounting techniques the primary reliability hazard is thermally induced fatigue failure of the solder fillets. This fatigue is caused by cyclic thermal stresses which are generated by variations both in ambient temperature and power dissipation within components. Such behaviour will ultimately constitute a 'wear-out' phenomenon in the majority of practical situations. The requirement is, therefore, to develop testing techniques to determine whether a particular surface mounted assembly will have a satisfactory life under the expected service conditions.

Previous studies have defined solder joint failure either by the visually observed presence of cracks or total electrical failure of the joint. Both these criteria however have disadvantages. Visual inspection is time consuming and the extent of cracking may only be fully determined by the destructive sectioning of the solder joint. Furthermore, the electrical performance of a component may be degraded by poor contacts before total failure of the connections to it.

The ready availability of 'zero-ohm' thick film jumper chips allows the possibility of making detailed resistance measurements without the relatively large component resistance of resistor or the impedance values of capacitor chips swamping the much smaller resistance changes expected in the joint resistances. A program has therefore been established to apply temperature cycling tests to these devices. 


\section{EXPERIMENTAL DESIGN}

\section{Components}

The components used are 1206 size jumper chips. They are constructed using a thick film conductor on an alumina substrate and have nickel barrier plated terminations to prevent solder leaching.

\section{Measurement Techniques}

In order to easily study small changes of resistance, chains of components are connected in series and monitored using four-terminal resistance measurements. The experiment is also designed to allow individual four-terminal measurements of each component to be made in order to determine whether one particular component has been responsible for any observed change in the total chain resistance.

\section{Test Coupon}

The test coupons (Figure 1) have been designed to allow attachment of 120 jumper chips in series chains. They are manufactured using $1.6 \mathrm{~mm}$ FR-4. They are assembled using an epoxy adhesive (Amicon D 124F) and then double-wave soldered using $60 \mathrm{Sn} / 40 \mathrm{~Pb}$ solder. 


\section{Tests}

Thermal cycling tests have usually been conducted symmetrically about a mean temperature of approximately $35^{\circ} \mathrm{C}$ (e.g., -55 to $+125^{\circ} \mathrm{C} ;-40$ to $\left.+110^{\circ} \mathrm{C}\right)$, but there was reason to doubt that the severity of these tests was only related to the temperature range.

It was therefore decided to test the effect of maximum cycle temperature by using tests with a fixed lower temperature of $-55^{\circ} \mathrm{C}$, but a number of different maximum temperatures. The test cycles used were $-55^{\circ} \mathrm{C}$ to $5^{\circ} \mathrm{C},+65^{\circ} \mathrm{C},+95^{\circ} \mathrm{C},+110^{\circ} \mathrm{C}$ and $+125^{\circ} \mathrm{C}$ all at 12 cycles per day and a rate of change of temperature of $3.5^{\circ} \mathrm{C}$ per minute (Figure 2). As a result the dwell times at both the maximum and minimum temperatures will be different for the different cycles.

The environmental chamber used was a LEC CL10HB, controlled by a PET microcomputer to give maximum flexibility in cycle profile.

In addition to these temperature cycling tests, two separate groups of jumper chips have been subjected to high temperature exposure tests. One group was tested in accordance with M1L-R-55342 paragraph 4.7.6. (100 hours at $\left.+125^{\circ} \mathrm{C}\right)$ and the second group was subjected to a similar test, but at a temperature of $+95^{\circ} \mathrm{C}$. These tests were undertaken in order to assess whether any drift in component resistances would affect the results of the temperature cycling tests.

\section{RESULTS}

The results of temperature cycling over the five ranges are shown in Figure 3. All measurements were taken at room temperature $\left(20^{\circ} \mathrm{C}\right)$. Figure 3 demonstrates that the 
largest increase in resistance occurs in cycling from $-55^{\circ} \mathrm{C}$ to $+95^{\circ} \mathrm{C}$ with smaller increases occurring due to cycling to higher and lower peak temperatures. Detailed examination of individual jumper resistances reveals that, rather than one or two components accounting for the resistance rise, there is a general trend upwards in resistances. This is illustrated in the histogram of Figure 4 where the total resistance of each jumper is shown before and after cycling between $-55^{\circ} \mathrm{C}$ and $+95^{\circ} \mathrm{C}$. Similar results were obtained for cycling over the other temperature ranges.

In the high temperature exposure at $+125^{\circ} \mathrm{C}$ an average change in jumper resistances of $+0.3 \mathrm{~m} \Omega$, amounting to an overall chain resistance change of $\approx+0.5 \%$, was observed.

In the $+95^{\circ} \mathrm{C}$ high temperature exposure test there were even smaller resistance changes, i.e., an average change in individual jumper resistances of $+0.1 \mathrm{~m} \Omega$ which amounts to an $\approx+0.2 \%$ change in overall chain resistance.

These resistance changes are well below those observed in the temperature cycling tests and it can therefore be concluded that temperature cycling changes are not caused by drifting of the component resistances.

\section{DISCUSSION}

Thermal stresses are caused by differential thermal expansion between component and substrate. This leads to shear strains in the solder fillet. Figure 5 shows an idealised component attachment. The thermal strain At for such an attachment is given by:-

$$
\Delta \varepsilon=L\left(\alpha_{c} \Delta T_{c}-\alpha_{s} \Delta T_{s}\right) / h
$$

Where: $L$ is the component length 
$h$ is the solder joint thickness

$\alpha_{c}$ and $\alpha_{s}$ are the thermal expansion coefficients of component and substrate

$\Delta T_{c}$ and $\Delta T_{s}$ are the changes in temperature of component and substrate.

This strain may be absorbed in three ways: elastic deformation of the whole structure $\left(\varepsilon_{e}\right)$, instantaneous plastic deformation of the solder fillet $\left(\varepsilon_{i}\right)$ and creep or time dependent plastic deformation of the solder fillet $\left(\varepsilon_{c}\right)$.

At room temperature and above the solder creep is rapid and the elastic strain quickly falls to zero. Hence the total plastic strain $\left(\varepsilon_{p}\right)$ may be assumed to be:-

$$
\varepsilon_{p}=\varepsilon_{i}+\varepsilon_{c}=\varepsilon
$$

The fatigue life of a material may be calculated using the Coffin-Manson relation [4]:-

$$
N_{f}=\left(\frac{\varepsilon_{f}}{2 \varepsilon_{p}}\right)^{2}
$$

where $N_{f}$ is the number of cycles to failure and $\varepsilon_{f}$ is the fracture ductility of the material. The fracture ductility of solder, however, increases substantially with temperature (Figure 6 [5]) so that a given level of strain will cause less damage when absorbed at a higher temperature.

From (3) the damage per cycle $(D)$ can be obtained where a change level of 1 represents failure:-

$$
D=\left(\frac{2 \varepsilon_{p}}{\varepsilon_{f}}\right)^{2}
$$


Assuming a linear damage summation, i.e., that the damage per cycle is the sum of the damage caused by each finite change in strain $\Delta \varepsilon$, the damage per cycle may be expressed as:-

$$
D=\left(\sum_{T_{\min }}^{T_{\max }} \frac{\Delta \varepsilon}{\varepsilon_{f}(T)}+\sum_{T_{\max }}^{T_{\min }} \frac{\Delta \varepsilon}{\varepsilon_{f}(T)}\right)^{2}
$$

For a temperature cycling test $\Delta T_{c}=\Delta T_{s}=\Delta T$ (equation 1 ), so from equation one we obtain:-

$$
\Delta \varepsilon=\Delta T\left(a_{c^{-}} a_{s}\right) L / h=k \Delta T
$$

The fracture ductility $\left(\varepsilon_{\mathrm{f}}\right)$ for a given temperature may be approximated by the function:-

$$
\varepsilon_{f}=a e^{b T}
$$

Using Equations (5), (6) and (7) one can calculate the damage expected to be caused by the idealised temperature cycle shown in Figure 7. It is assumed that for the step increase in temperature all the strain is absorbed at the new temperature and that the subsequent reduction in temperature is slow enough for the strain to be absorbed at the temperature at which it was generated. In a practical situation some of the strain will be absorbed at lower temperatures and thus the damage will be higher.

The damage caused by the step change in temperature from $T_{\min }$ to $T_{\max }$ may therefore be expressed by:-

$$
D=\left[\frac{k\left(T_{\max }-T_{\min }\right)}{a e^{b T_{\max }}}\right]^{2}
$$


And the damage caused by the slow change in temperature from $T_{\max }$ to $T_{\min }$ is:-

$$
D=\left[\int_{T_{\max }}^{T_{\min }} \frac{k}{a e^{b T}} d T\right]^{2}={ }_{T_{\max }}^{T_{\min }}\left[\frac{k}{a b} e^{-b T}\right]
$$

From Equations (8) and (9) the total damage for the cycle is:-

$$
D=k^{2}\left[\frac{T_{\max }-T_{\min }}{a e^{b T_{\max }}}+\frac{e^{-b T_{\min }}-e^{-b T_{\max }}}{a b}\right]
$$

This equation has been plotted against maximum cycle temperature in Figure 8 using a minimum cycle temperature of $-55^{\circ} \mathrm{C}$. The graph does show that the maximum damage is expected for cycling from $-55^{\circ} \mathrm{C}$ to $+95^{\circ} \mathrm{C}$, with slightly less damage for higher maximum temperatures.

This effect is however small and is insufficient to explain the experimental results obtained. Therefore there must be other factors involved. These may be:-

(a) The large drop in the modulus of elasticity of the resin matrix of the FR-4 PCB at its glass transition temperature of $110^{\circ} \mathrm{C}$. This may result in less of the strain being plastically absorbed at higher temperatures.

(b) Other changes in the solder such as work hardening/annealing processes altering the solder's mechanical properties and consequently the way in which the strain is absorbed. Intermetallic growth or changes in the bulk resistivity of the solder fillet may also occur. 


\section{CONCLUSIONS}

(i) Both theoretically and practically it has been shown that the effect of temperature cycling on surface mounted devices depends on the cycling temperatures. For a minimum temperature of $-55^{\circ} \mathrm{C}$, the most effective top temperature with regard to causing resistance increase in the solder fillets is $95^{\circ} \mathrm{C}$.

(ii) Temperature cycling tests from $-55 \%$ to temperatures between $+5^{\circ} \mathrm{C}$ and $+125^{\circ} \mathrm{C}$ result in a quite complex interaction of the changes in mechanical properties of the materials involved.

\section{ACKNOWLEDGEMENTS}

The authors thank STC Telecommunications plc for financial support during the course of the study. Particular thanks are given to Mr W. J. Young (STC Components), Mr M. J. Harris (STC Defence Systems) and Mr J. Mindham (STC Transmission Products) for valuable comments and interest. 


\section{REFERENCES}

1. Engelmaier, W., 'Reliability in Surface Mounted Assemblies. Controlling Thermal Expansion Mismatch Problems', ISHM/BABS/IMF Symposium, June (1986).

2. Sinnadurai, N., Cooper, K. and Woodhouse, J., 'Assessing the Joints in Surface Mounted Assemblies', Microelectronics Journal, Vol. 17, No. 2, pp 21-31 (1986).

3. Hall, I. M., 'Strain Measurement during Thermal Chamber Cycling of Leadless Ceramic Chip Carriers Soldered to Printed Boards', Proceedings 34th Electronic Components Conference, pp 107-116 (1984).

4. Manson, S. S., 'Thermal Stress and Low-cycle Fatigue', McGraw-Hill, New York (1966).

5. Ainsworth, P. A., 'The Formation and Properties of Soft Soldered Joints', International Tin Research Institute Publication, November (1971). 


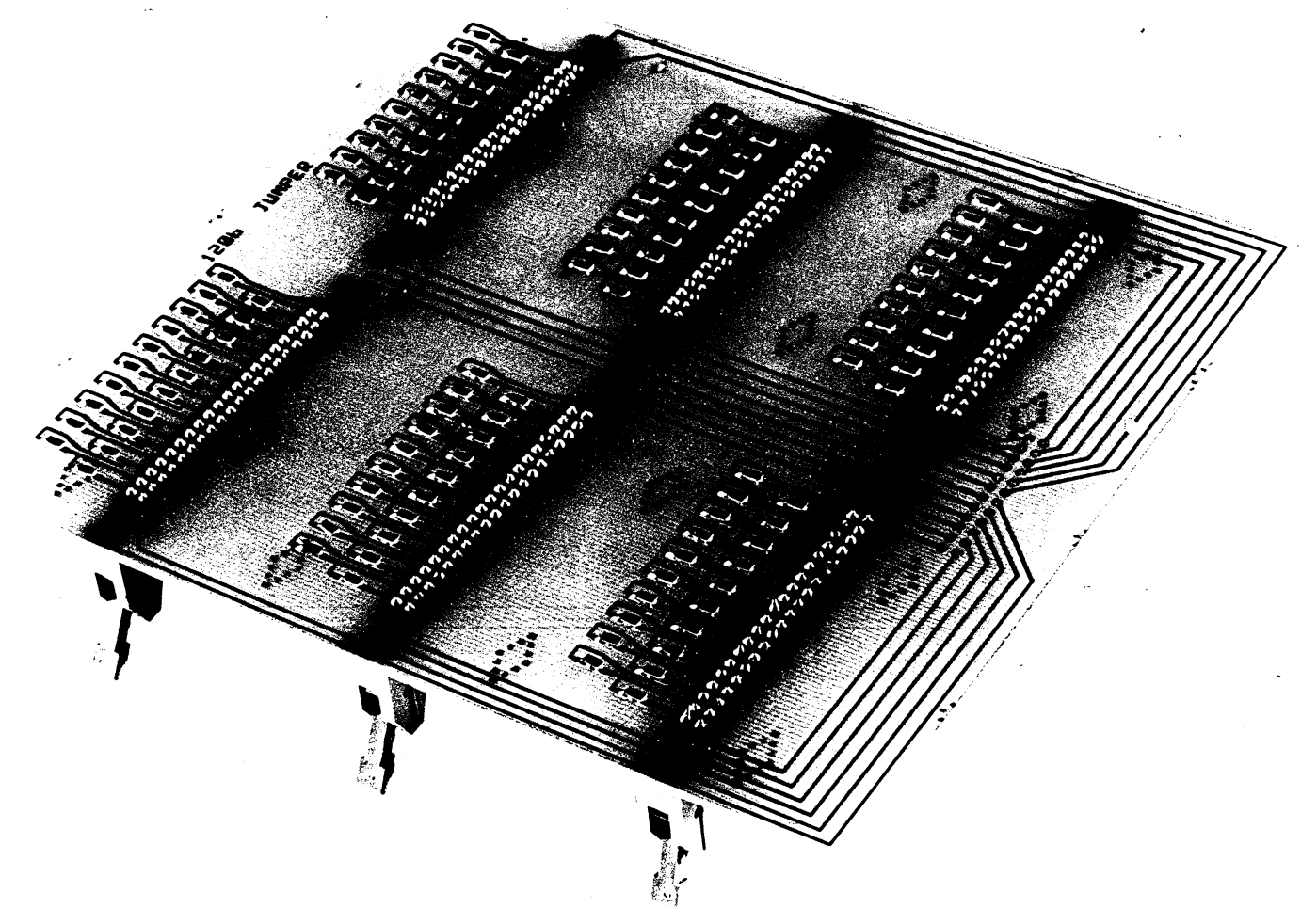

Figure 1

Temperature Cycle Test Coupon 


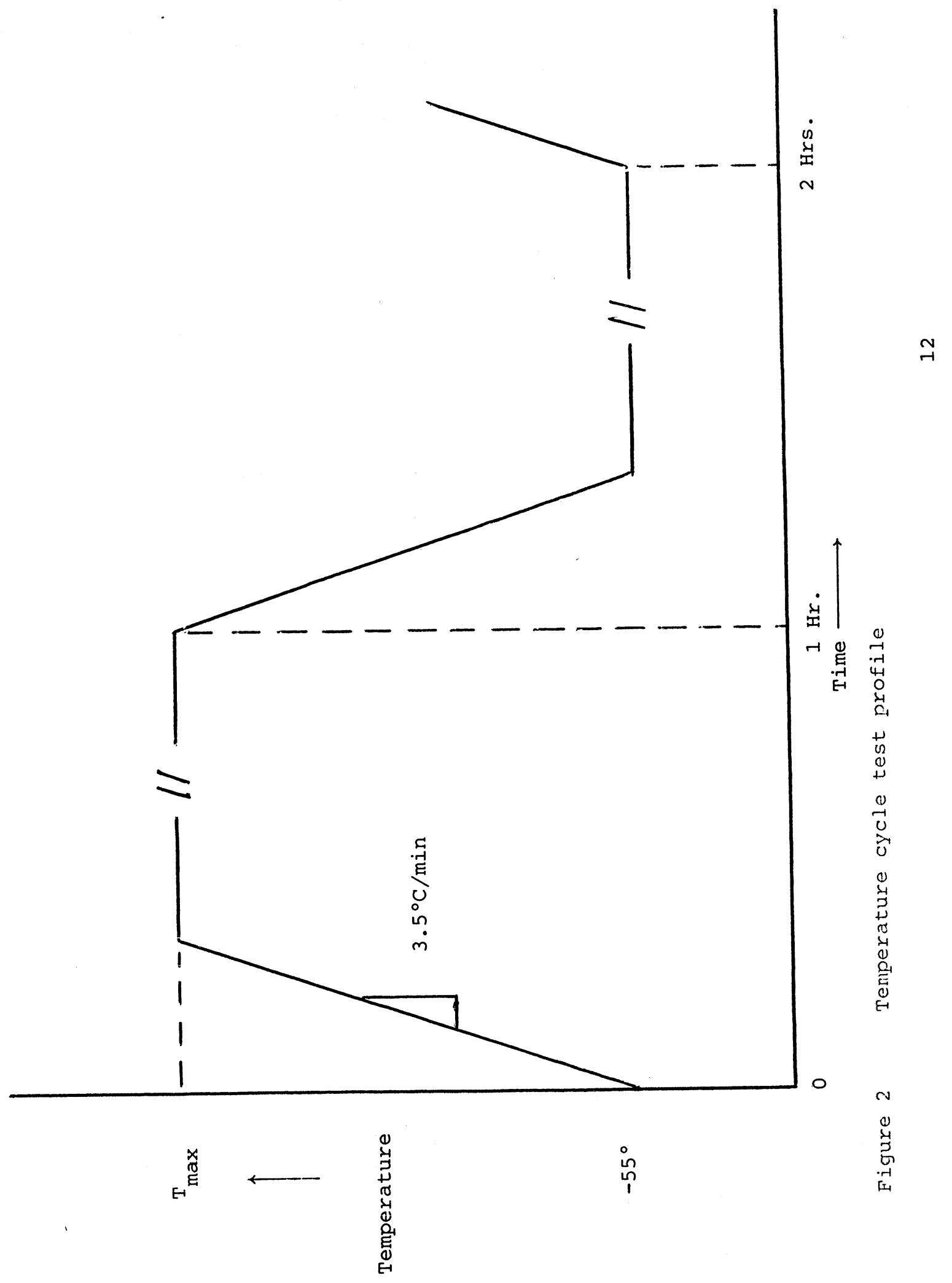




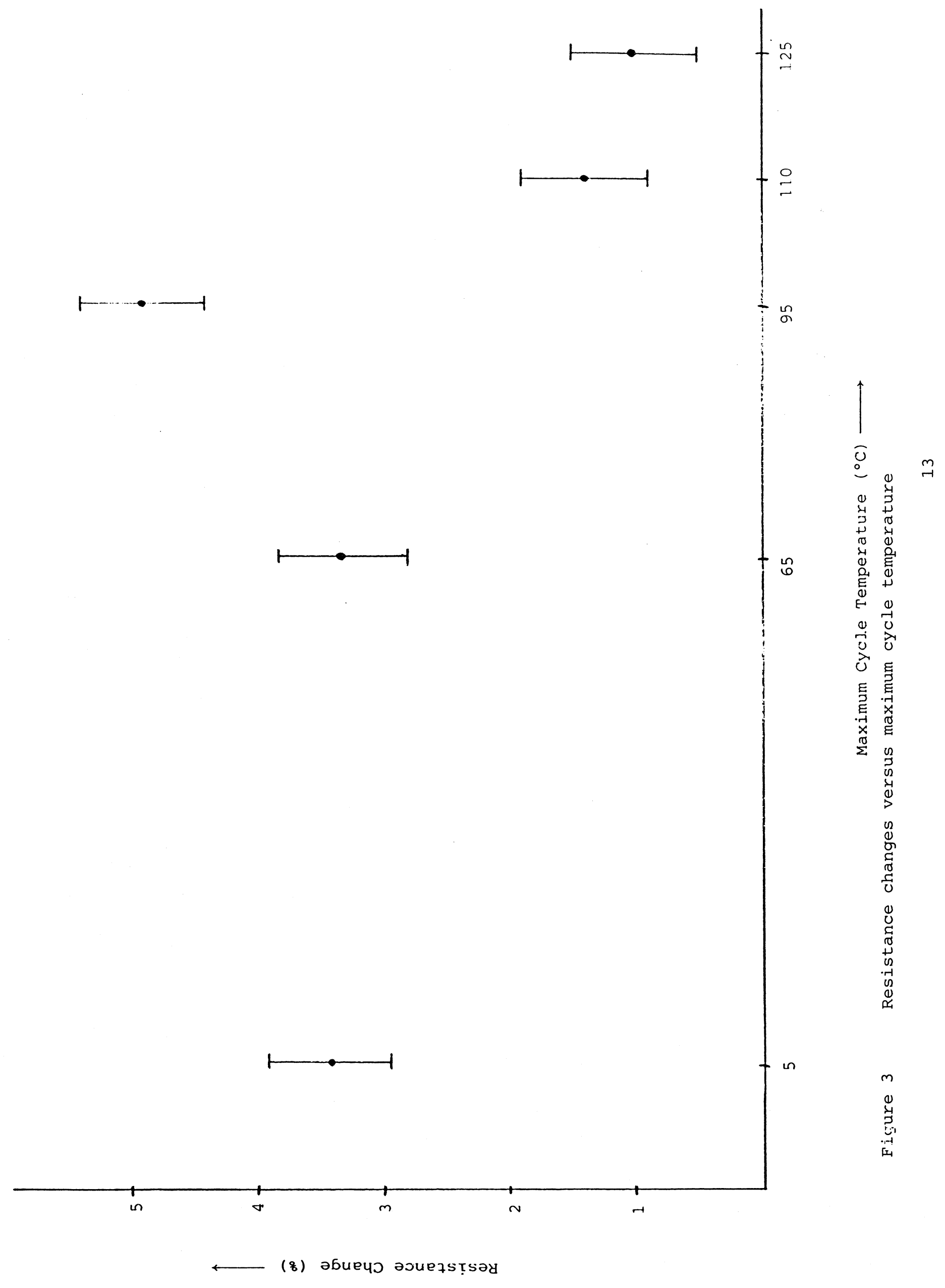




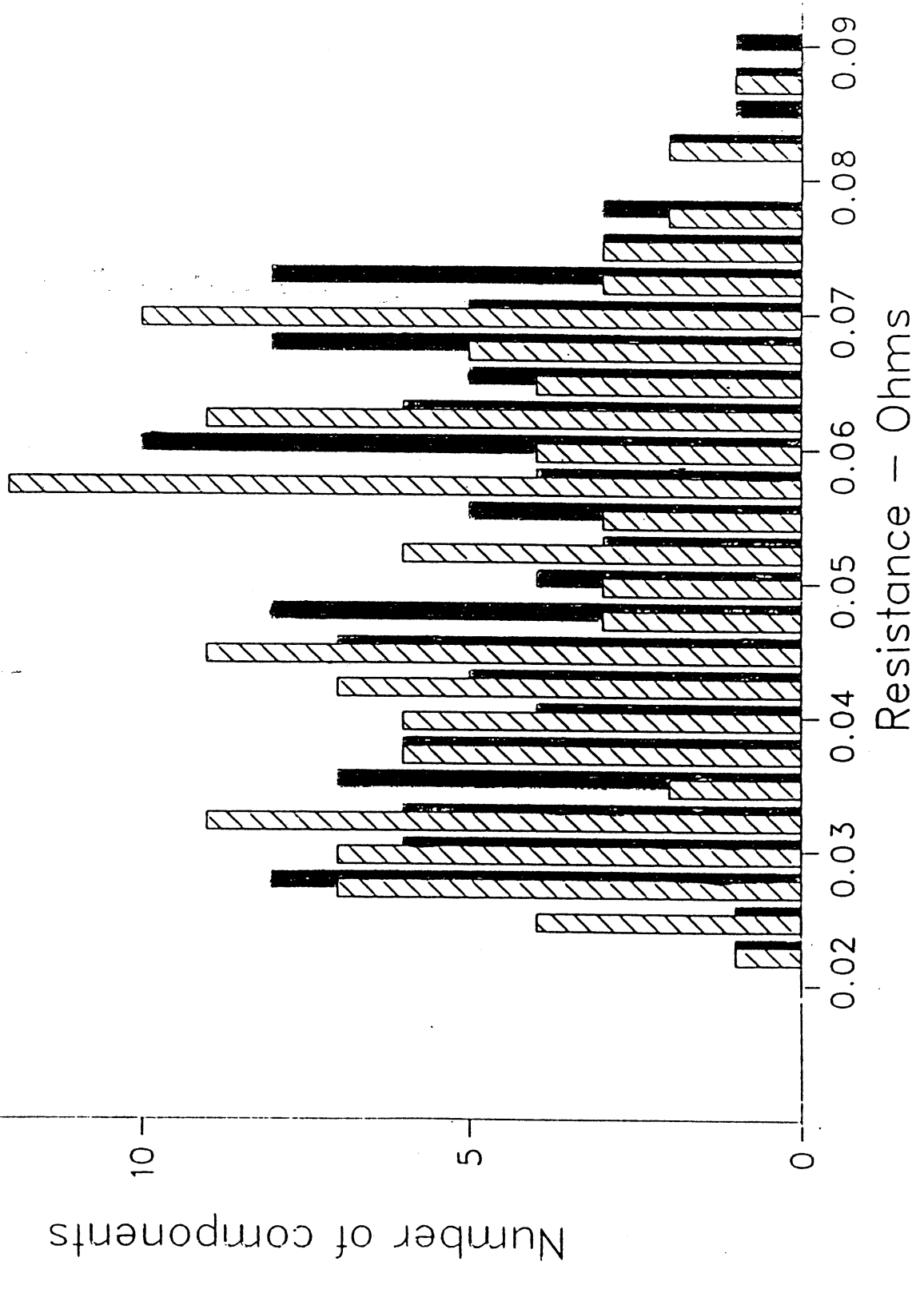




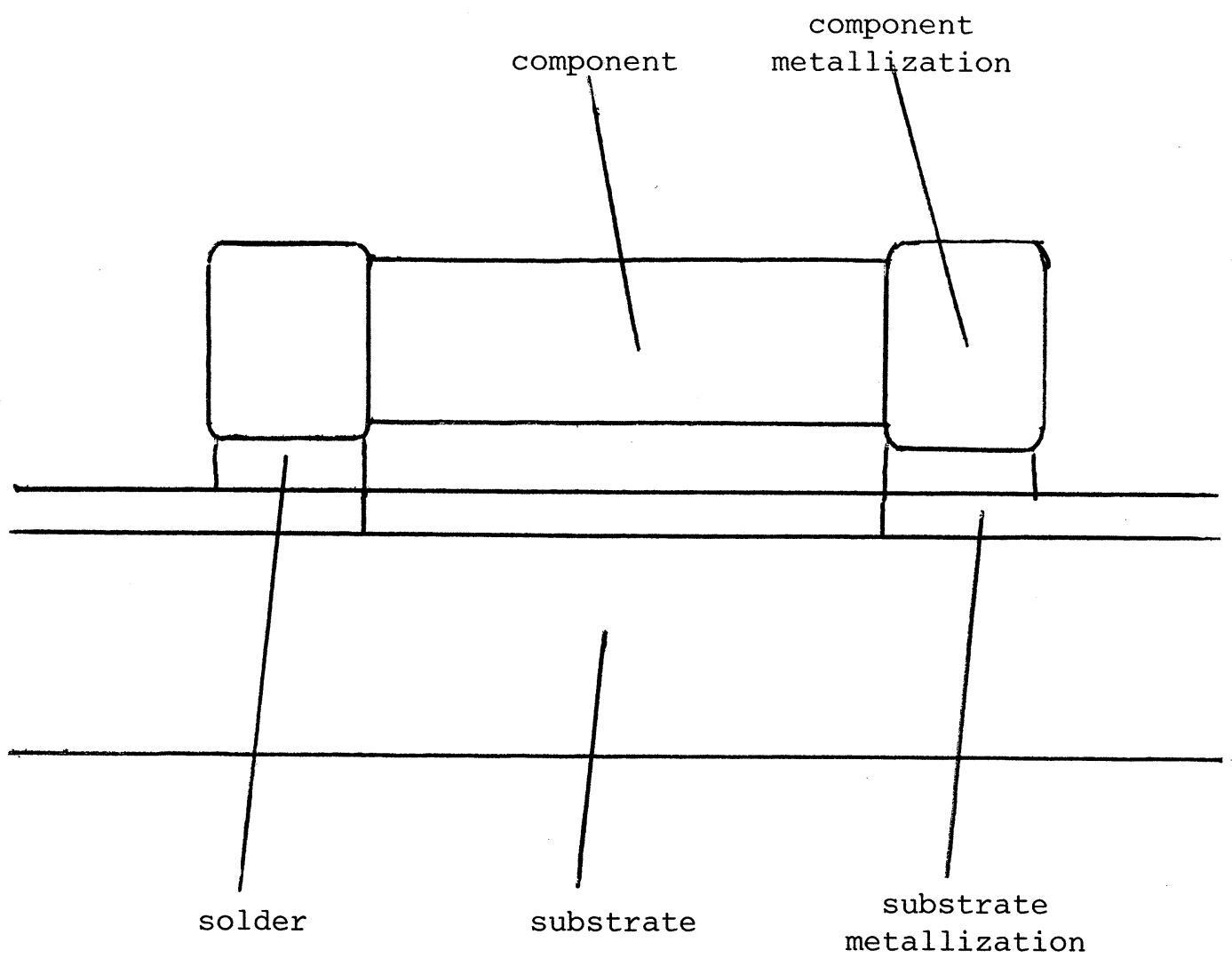

Figure 5

Idealised component attachment 


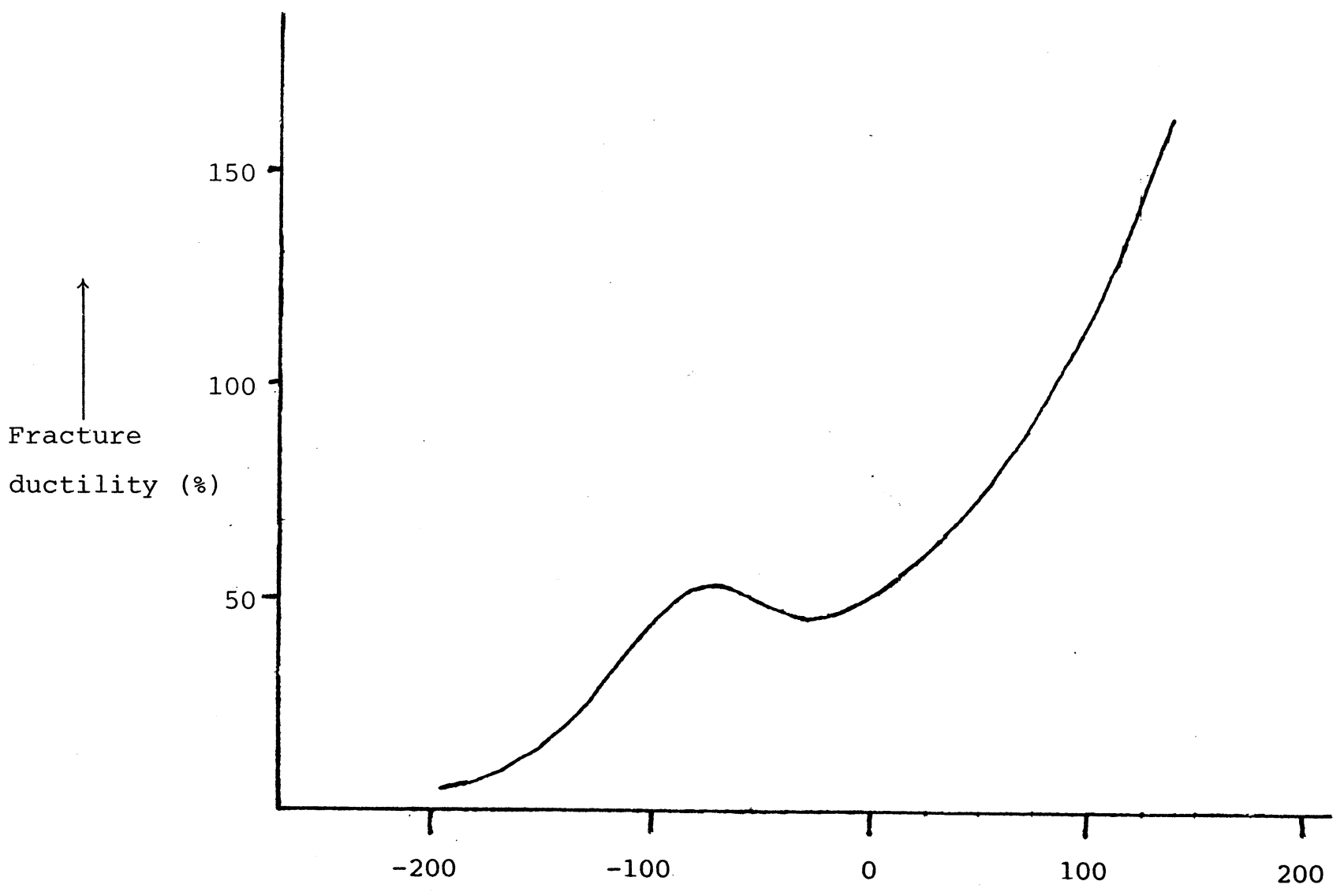

Temperature $\left({ }^{\circ} \mathrm{C}\right)$

Figure 6 Variation of fracture ductility with temperature for $60 \mathrm{Sn} / 40 \mathrm{~Pb}$ solder [5] 


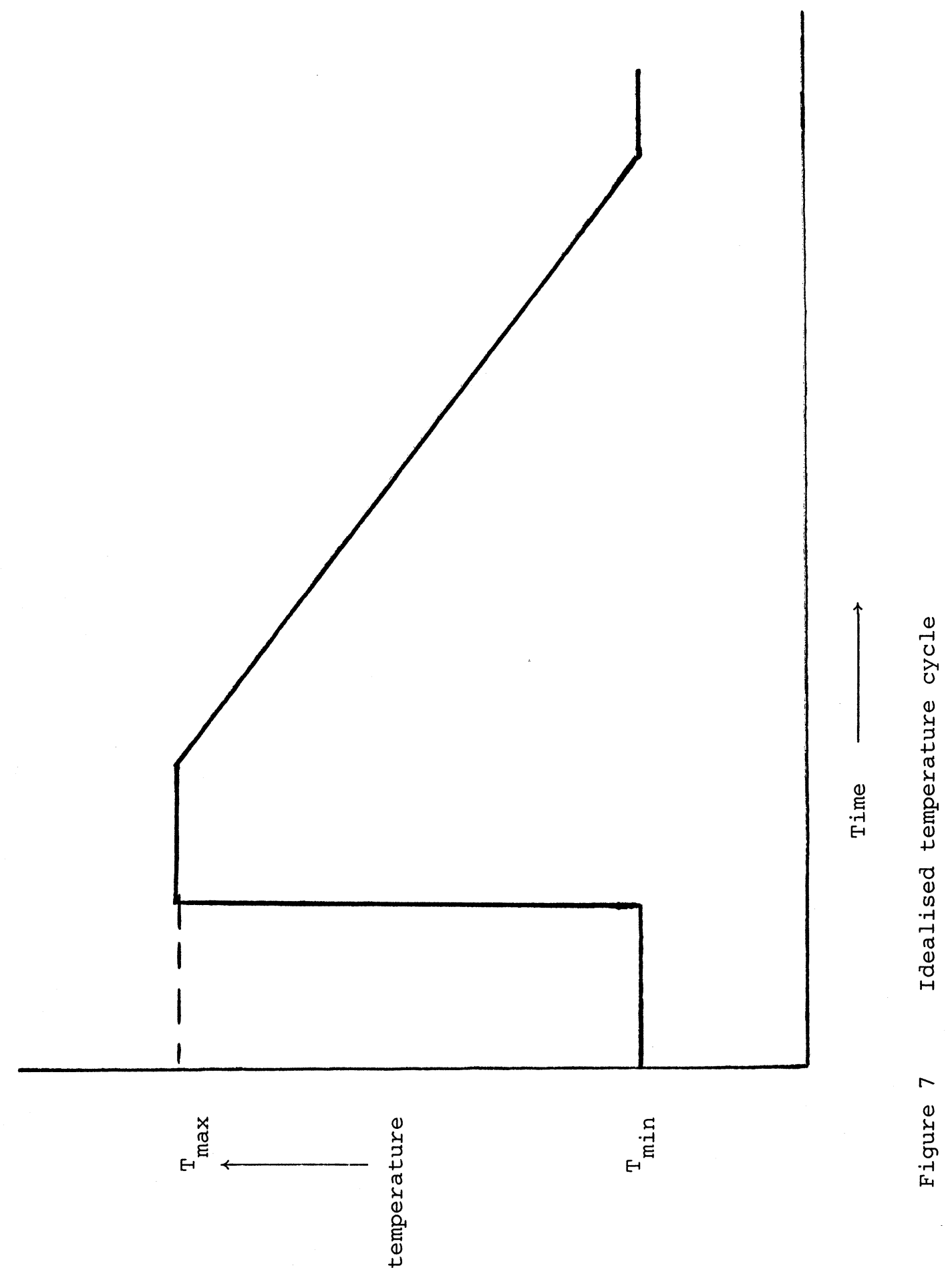




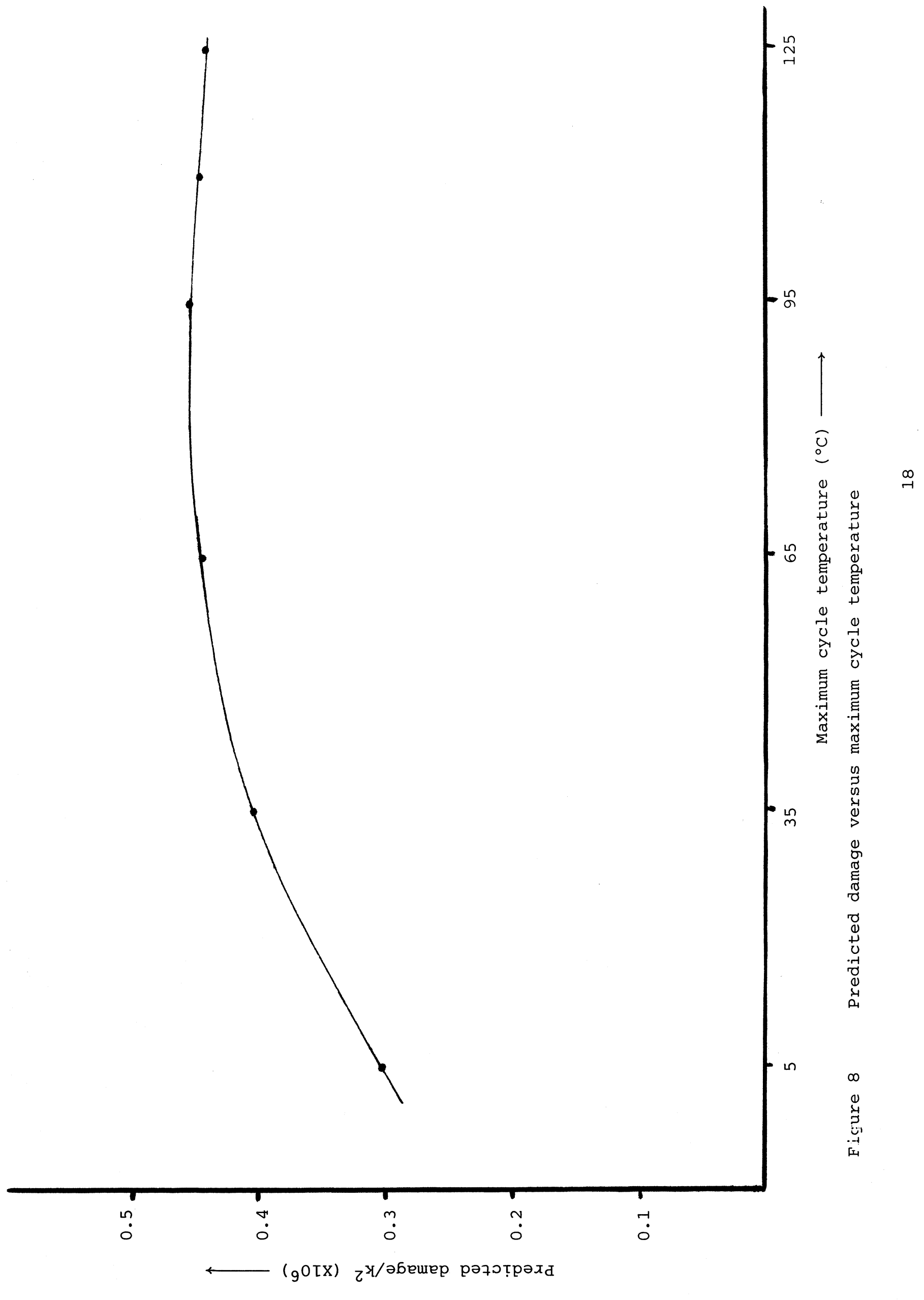

